\title{
Experimental Models for Activtation Mechanism of Pressureless Infiltration in the Non-Wetting Steel-Alumina MMC System**
}

\author{
By Srdan Vasić, Bernard Grobéty, Jakob Kuebler, Philippe Kern, Thomas Graule*
}

Metal Matrix Composite (MMC) combine physical and chemical properties of metallic and ceramic materials, such as the good thermal conductivity of metals and the high hardness of ceramics. Different manufacturing techniques such as squeeze casting, pressure infiltration or powder metallurgy have been described in previous studies. ${ }^{[1-4]} \mathrm{MMC}^{\prime}$ s made of $\mathrm{Al}_{2} \mathrm{O}_{3}$ (alumina) and high melting Fe-base alloys (e.g., $\mathrm{X} 3 \mathrm{CrNiMo13}-4$ ) meet the requirements for certain application in food, pharmaceutical and automotive industry. ${ }^{[5]} \mathrm{A}$ formfree and advantageous way to produce MMC's is the infiltration of porous ceramic performs by metal melts. Problems arise for metalic melts that do not wet the ceramic substrate. Forced infiltration by setting the melt under pressure is a (costly) way to overcome the negative capillary forces. A more economic technique to enhance wettability is the introduction of a wetting activator into the porous preform. The activator for example titanium is mixed with the ceramic powder used for the preform fabrication. In systems studied so far, such as $\mathrm{SiC}$ and AlN preforms infiltrated by bronze and Fe-base alloys, the enhancement of the wettability is due either to the formation of a wettable layer through the reac-

[*] Dr. S. Vasić, Prof. B. Grobéty

Technical Mineralogy Group

Institute of Mineralogy and Petrography

University of Fribourg

Pérolles, Ch. du Musée 6, CH-1700 Fribourg, Switzerland

J. Kuebler, Dr. T. Graule

Empa, Swiss Federal Laboratories for Materials Testing and Research

Laboratory for High Performance Ceramics

Ueberlandstrasse 129, CH-8600 Duebendorf, Switzerland

Contact: jakob.kuebler@empa.ch

Dr. P. Kern

Empa, Swiss Federal Laboratories for Materials Testing and Research

Mechanics of Materials and Nanostructures

Feuerwerkerstrasse 39, CH-3602 Thun, Switzerland

[**] The author would like to thank Dr. P. Kappenberger (Empa, Swiss Federal Laboratories for Materials Testing and Research) for the AFM measurements of the alumina substrates. Especially I would like to thank B. Vogler and T. Schmidt for their help with the sputtering device at OC Oerlikon. tion of the activator with the ceramic substrate or to the lowering of the surface tension of the melt. Activation by Ti has been successfully used for the manufacturing of $\mathrm{Al}_{2} \mathrm{O}_{3}$ X3CrNiMo13-4 MMC, ${ }^{[4-7]}$ but textural observations and the linear infiltration kinetics observed in preliminary experiments are difficult to explain with the formation of reaction layer or the lowering of surface tension. ${ }^{[8-15]}$

Two types of experiments were, therefore, set up to elucidate the infiltration mechanisms in the alumina - steel system. A series of experiments was conducted with a model pore consisting of two juxtaposed parallel alumina plates separated by spacers. The gap simulates a single $2 \mathrm{D}$ pore. On the surface of one of the plates regular array of cylindrical $\mathrm{Ti}$ dots, which mimic $\mathrm{Ti}$ activator particles in the real preforms, were imprinted by lithographic methods. ${ }^{[16,17]}$ Preliminary experiments on preforms have shown that activator concentration and size are important parameters for infiltration. ${ }^{[18]}$ Therefore, model pores with different dot sizes and densities were prepared. The diameter of the dots and distances among them were tuned lithographically. The main advantage of this method is that variable arrays can be created which simulate different levels of activation. ${ }^{[16,17]}$ A second set of experiments were performed with preforms composed of two activated $\left(\mathrm{Al}_{2} \mathrm{O}_{3}-\mathrm{Ti}\right)$ and three non activated layers parallel to the melt flow direction. This experiments should reveal if $\mathrm{Ti}$ is mobile during the thermal treatment and spreads into the non-activated parts of the preform. For both types, a piece of alloy was placed on the top of the samples and heated up in a vacuum furnace.

\section{Experimental}

\section{Model Pore Experiments}

Alumina substrates $(15 \times 17 \times 2.5 \mathrm{~mm})$ for the model pore were supplied by Applied Ceramics (AC Europe, Schaan, Switzerland). The average surface roughness of $\sim 0.4 \mu \mathrm{m}$ (5 measuring areas) was determined by atomic force microscopy (AFM) using an easyScan ${ }^{\mathrm{TM}}$ (Schaefer Technology $\mathrm{GmbH}$; Kirchberg, Switzerland). The Ti pillars for the model pore experiments were depostited lithographically onto the alumina substrates surfaces. First a SU-8 2035 (MicroChem; Newton MA, USA) photosensitive layer was spin-coated (APT-Polos MCD200-NPP spin coater ; SPS, Ingoldstadt, Germany) onto the surface. The initial coating was perfomed with a spinning speed of $800 \mathrm{rpm}$ for $10 \mathrm{~s}$ then going to $5000 \mathrm{rpm}$ for $30 \mathrm{~s}$ using an acceleration of $300 \mathrm{rpm} \mathrm{s}^{-1}$, yield- 

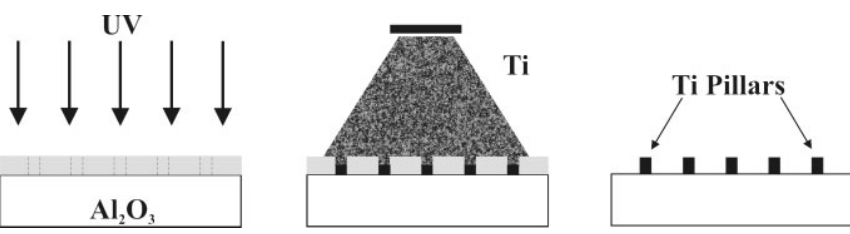

Fig. 1. Schematic representation of the lithographic process (from left to right)-1. exposure of the photoresist (grey) 2. Ti sputtering 3. The finished substrate after resist removal.

ing a resist thickness of $\sim 30 \mu \mathrm{m}$. The photoresist was prebaked at $65^{\circ} \mathrm{C}$ for $1 \mathrm{~min}$ and than placed for $6 \mathrm{~min}$ onto a hotplate at $95^{\circ} \mathrm{C}$. Exposure of the resist was carried out using a maskless UV exposure system working with digital micromirror device (DMD) technology, allowing for pixel controlled contact-free exposure (SF-100, Intelligent Micro Patterning, LLC, Florida) device (Fig. 1). The patterns consisted of hexagonally arranged circular dots with different diameters and center to center (Tab. 1). An exposure time of $4.75 \mathrm{~s}$ was found to be optimal. Post-exposure baking was performed at a temperature of $65^{\circ} \mathrm{C}$ for $2 \mathrm{~min}$ followed by $95^{\circ} \mathrm{C}$ for $4 \mathrm{~min}$. After cooling down to RT, the photoresist was developed under controlled stirring for $5 \mathrm{~min}$ in SU-8 developer (MicroChem; Newton MA, USA).

The resist structure on an area of $10 \times 15 \mathrm{~mm}$ was afterwards characterised by SEM using a FEI XL 30 Sirion FEG (Phillips; Eindhoven, Netherlands) and a Stylus Profilometer (Veeco; Mannheim, Germany) (Fig. 2(a,b)).

The lithographic processed alumina subtrate was coated with a $10 \mu \mathrm{m}$ thick titanium layer with an industrial sputter device DVD-Sprinter (OC Oerlikon; Balzers, Liechtenstein), using a TGd1 titanium target (Disc AG, Vaduz, Liechtenstein). The photoresist was removed from the exposed areas with a SU-8 Remover (Microchem; Newton MA, USA) at $85^{\circ} \mathrm{C}$ under stirring for $45 \mathrm{~min}$. The final structure consisted of an alumina substrate with an hexagonal array of well defined Ti pillars (Fig. 3).

A coated and an uncoated alumina substrate were juxtaposed and separated by spacers and fixed with alumina wedges (Fig. 4(a)). Spacers with a thickness of $200 \mu \mathrm{m}$ were supplied by Applied Ceramics (AC Europe, Schaan, Switzerland). The dimension of the gap between the substrates and spacers was $0.2 \times 10 \mathrm{~mm}$ with a depth of $17 \mathrm{~mm}$ and represented a single pore with a defined melt flow direction (Fig. 4(b)). The alloy used for the experiments is a conventional ferrite X3CrNiMo13-4 (Böhler AG; Switzerland, Walisellen). A steel cube (edge; $3 \mathrm{~mm}$ ) was placed on the top of the gap.

Table 1. Dot diameters and distances between dots.

\begin{tabular}{lcccccc} 
& TR-20 & TR-10 & TR-5 & TF-20 & TF-10 & TF-5 \\
\hline Distances $[\mu \mathrm{m}]$ & 150 & 250 & 500 & 75 & 150 & 300 \\
Diameter $[\mu \mathrm{m}]$ & 500 & 500 & 500 & 125 & 125 & 125
\end{tabular}
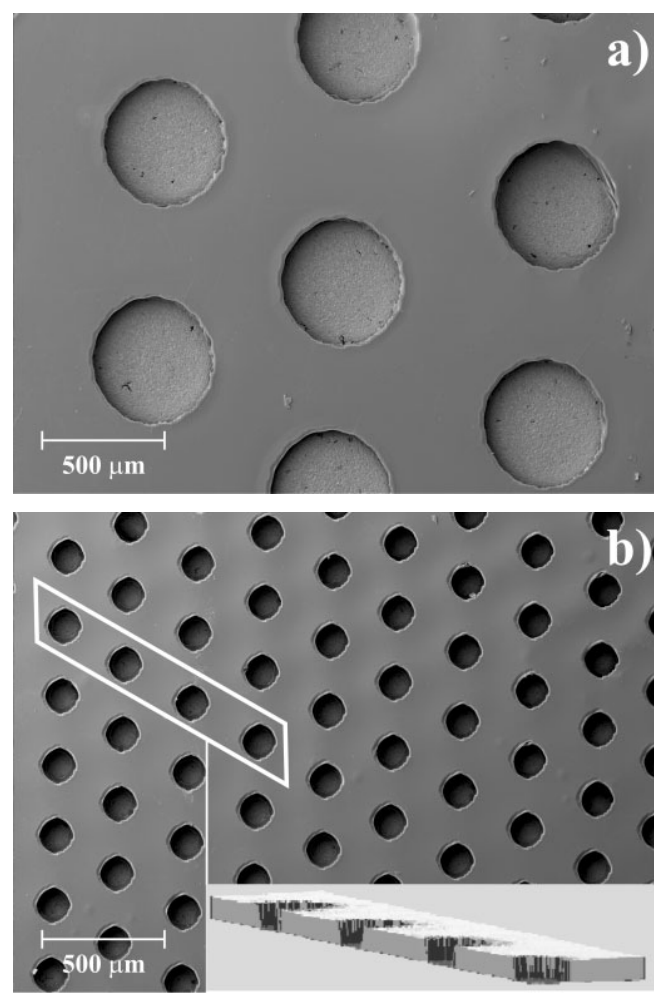

Fig. 2. a) SEM Image of a photoresist mask: a) TR-20 and b) TF-20 sample Inset and white box in b: crossection of a TR-20 mask (Stylus Profilometer). No material is left in the holes after exposure

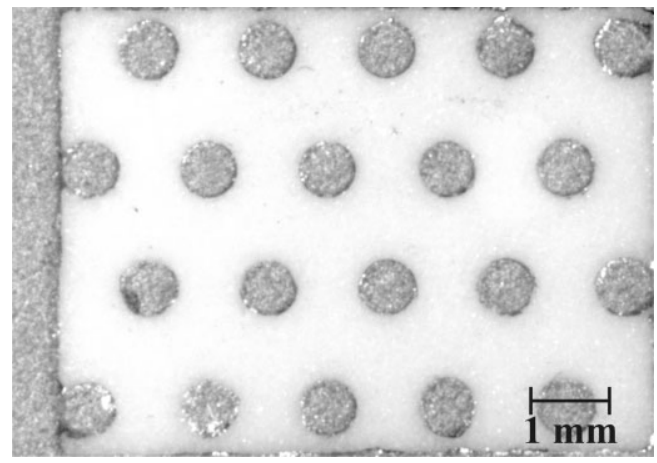

Fig. 3. TF-20 sample after sputtering and resist removal.

In preliminary studies by Vasic et al. the influence of activation content as well as particle diameter of activator on the infiltration behaviour within porous ceramic powder compacts were investigated. ${ }^{[18]}$ It was observed that the infiltration behaviour improves with increasing Ti particle number, but not with increasing the concentration using larger Ti particles. In order to simulate variable density and size of the activator particles three liltographic masks were prepared. Sample notation, distance between dots and dot diameters are summarised in Table 1. A separate substrate was produced simulating the case where $\mathrm{Al}_{2} \mathrm{O}_{3}$ particles, and thus the whole substrate surface too, are covered with titanium and labelled T1. 


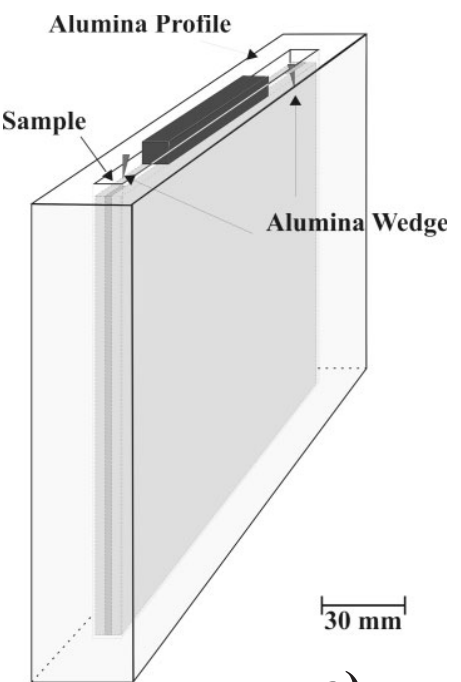

a)

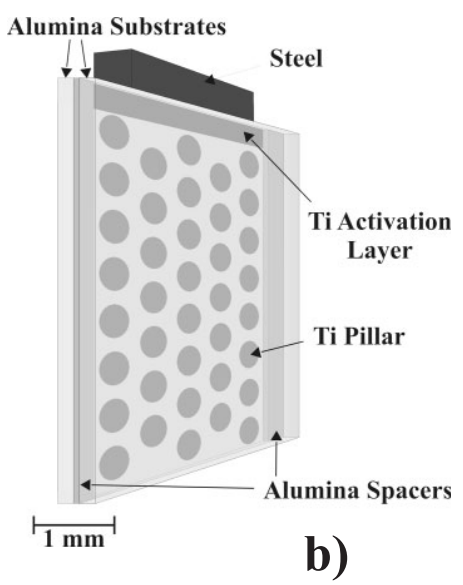

Fig. 4. a) Schematic representaion of a model pore and b) the distribution of Ti dots.

The model pore samples were heated with a heating rate of $5^{\circ} \mathrm{C} / \mathrm{min}$ to $1600^{\circ} \mathrm{C}$ and kept at the latter for 15 (D15) resp. $45 \mathrm{~min}$ (D45). The experiments were made with a Super VII vacuum furnace (Vacuum Industries; Summerville MA, USA) operated with a pressure of $2.5 \cdot 0^{-4}$ mbar. The atmosphere corresponds to ambient air.

\section{Layered Preform Experiments}

The preforms consisted of a lamellar preform with alternating $2 \mathrm{~mm}$ wide layers of alumina (Alumina WSK120, Treibacher, Germany; A100: $d_{50}=151 \mu \mathrm{m}, \mathrm{A} 20: d_{50}=33 \mu \mathrm{m}$ and layers consisiting of a mixture of $80 \mathrm{wt} \%$ alumina A100 and $20 \mathrm{wt} \%$ of titanium T40 (Titanium Gd1-40, TLS Technik GmbH \& Co., Germany; $d_{50}=54 \mu \mathrm{m}$ ) (Fig. 5). Details on the fabrication and characteristics of the powder mixture can be found elsewhere. ${ }^{[16]}$ The layered powder assemblies were densified in an uniaxial press $(65 \mathrm{MPa})$ resulting in preforms with a dimension of $\sim 1 \times 1 \times 1 \mathrm{~cm}^{3}$ (Fig. 5). Alloy pieces were placed on top of the preforms. Heating conditions and

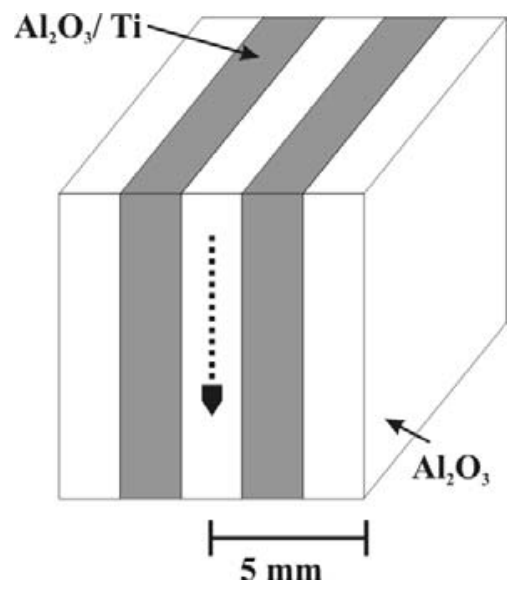

Fig. 5. Schematic representation of the preform consisting of alternating lamella of pure $\mathrm{Al}_{2} \mathrm{O}_{3}$ and $\mathrm{Al}_{2} \mathrm{O}_{3}-\mathrm{Ti}$ powder layers. The alloy is placed on the top of the preform. (dashed arrow indicates infiltration direction)

dwell times were the same as for the model pore experiments. Therefore the labelling D15 for a dwell time of $15 \mathrm{~min}$ and D45 for 45 min respectively were chosen.

\section{Results, Discussion and Conclusions}

The Ti dots in all model pore experiments were covered by steel, but not the alumina walls between the dots. For dwell times of $15 \mathrm{~min}$, the dots were partially covered with steel whereas after dwell times of 45 min most of the pillars were fully covered and showed an increase in diameter (max. $+50 \mu \mathrm{m}$ ) (Fig. 6). The Ti coated surface of sample T1 was covered up to $60 \%$ by alloy and inhomogeneous streak like melt propagation was observed. The composition of the alloy covering the dots determined by EDX measurements consisted of $\sim 80$ wt.- $\%$ Fe and $\sim 20$ wt.- $\%$ Ti.

Figure 7(a) shows the onset of infiltration in layered A20T40 preform after a dwell time of $15 \mathrm{~min}$. For the sample with the coarser alumina, A100T40, $15 \mathrm{~min}$ are sufficient to fill $60 \%$ of the pore volume (Fig. 7(b)). For both dwell times no alloy was found in the layers without $\mathrm{Ti}$ activator. The presence of steel depositions on the $\mathrm{Ti}$ dots in the model pores and the Ti particles in the layered preforms, which are not in contact with the steel source on top of the sample, can only be explained by transport of steel components through the gas phase. There are two possible explanation for the condensation of steel onto the Ti surfaces: a change of temperature or supersaturation of the gas phase relative to a certain alloy composition. Temperature gradients may be excluded, because the maximum steel layer that can be deposited, assuming that the entire steel components present in the gas phase of the model pore or in the pore network of the preform condensate during cooling from the maximum temperature to the melting temperature of the alloy, is around $2 \eta \mathrm{m}$ (calculated using the partial pressure of pure iron at $1600^{\circ} \mathrm{C}$ ). The second driving force, supersaturation, is more likely. Gas transport and condensation of steel on the $\mathrm{Ti}$ "islands" is thus 

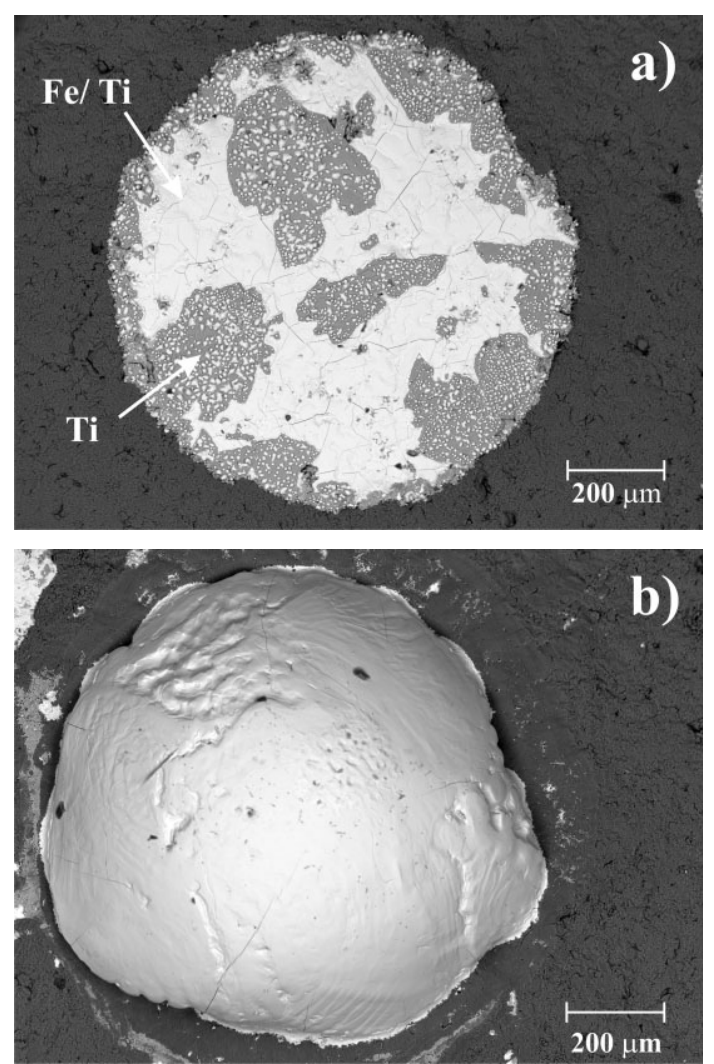

Fig. 6. a) Ti dot of a TR-20 sample partially covered by alloy at a dwell time of $15 \mathrm{~min}$ and b) completely covered after a dwell time of $45 \mathrm{~min}$.

considered to be the crucial steps in the activation mechanism for the present system, and not the modification of the surface properties of the preform material nor of the surface tension of the melt.

The increase in diameters of the dots in the model pore suggests a radial deposition rate of about 50 to $100 \mu \mathrm{m} / \mathrm{h}$, which is enough to form bridges between Ti particles in the preform setup. The average next nearest $\mathrm{Ti}$ interparticle distance in the activator containing layer is between 53 and $70 \mu \mathrm{m} .{ }^{[18]}$ As soon as such melt bridges are established, the steel melt can propagate along the existing melt surfaces.

A new activation mechanism for pressureless infiltration of non-wetting MMC systems has been demonstrated. Transport through the gas phase of the metal constituents and subsequent condensation on activator particles are the processes that lead to infiltration in the alumina-steel system. This discovery should facilitate the selection of the activator material (partial pressure, saturation, final steel composition). Further preform experiments are under way to investigate the infiltration kinetics of the alumina - steel MMC system.

Received: December 04, 2007 Final version: January 31, 2008
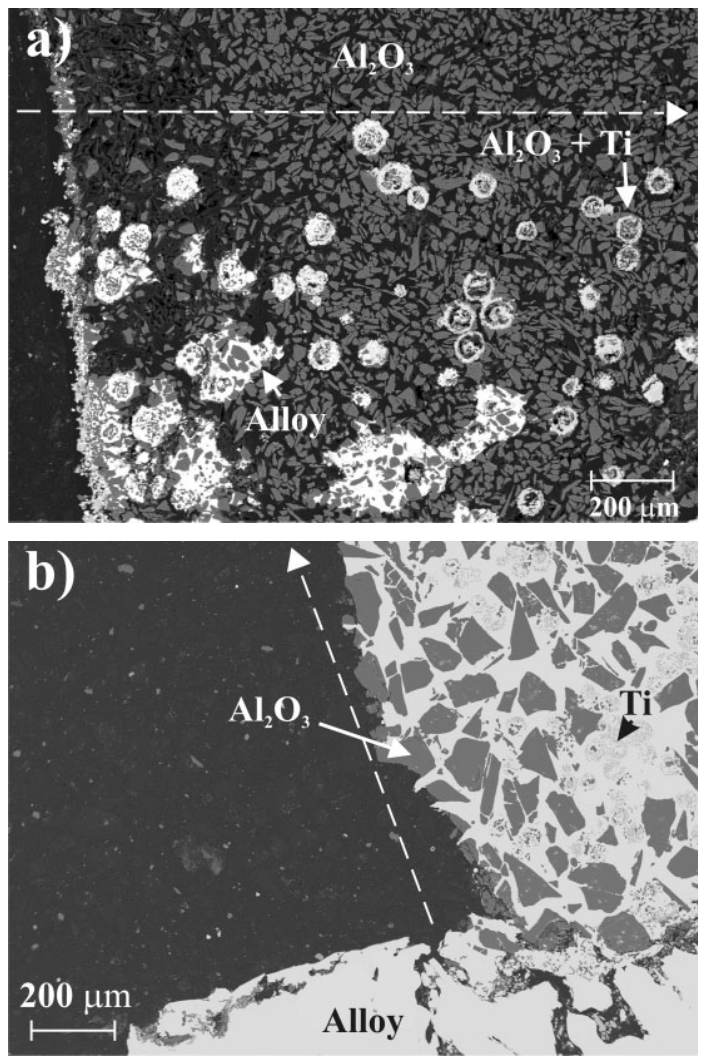

Fig. 7. a) BSE image of the boundary (white arrow, indicates also infiltration direction) between a layer with and without Ti particles after a dwell time of 15 min in a A20T40 sample. It is obvious that steel is only present in the $\mathrm{Al}_{2} \mathrm{O}_{3}$-Ti layer. b) Most alumina particle in the Ti free layer were pulled out during sample preparation because of poor mechanical stability of the steel free preform (A100T40; dewll time $30 \mathrm{~min}$ ).

[1] M. Rosso, J. Mater. Process. Technol. 2005, 175, 346.

[2] A. Mattern, B. Huchler, D. Staudenecker, R. Oberacker, A. Nagel, M. J. Hoffmann, J. Eur. Ceram. Soc. 2004, 24, 3399.

[3] C. A. Leon-Patino, R. A. L. Drew, Curr. Opin. Solid State Mater. Sci. 2005, 9, 11.

[4] K. Lemster, M. Delporte, T. Graule, J. Kuebler, Ceram. Int. 2006, 14, 323.

[5] K. Lemster, T. Graule, J. Kuebler, Mater. Sci. Eng. A 2005, 393, 229.

[6] K. Lemster, T. Graule, T. Minghetti, C. Schelle, J. Kuebler, Mater. Sci. Eng. A 2006, 420, 296.

[7] K. Lemster, T. Graule, J. Kuebler, Mater. Sci. Eng. A 2005, 393, 229.

[8] N. Eustathopoulos, M. G. Nicholas, B. Drevet, in Wettability at High Temp. 3, Pergamon, Oxford 1999, 2.

[9] F. Ortega-Celaya, M. I. Pech-Canul, J. Lopez-Cuevas, J. C. Rendon-Angeles, M. A. Pech-Canul, J. Mater. Process. Technol. 2007, 183, 368.

[10] K. M. Shorowordi, T. Laoui, A. S. M. A. Haseeb, J. P. Celis, L. Froyen, J. Mater. Process. Technol. 2003, 142, 738.

[11] J. M. Molina, E. Pinero, J. Narciso, C. Garcia-Cordovilla, E. Louis, Curr. Opin. Solid State Mater. Sci. 2005, 9, 202. 
[12] C. Garcia-Cordovilla, E. Louis, J. Narciso, Acta Mater. 1999, 47, 446.

[13] Y. Pan, X. S. Yi, J. L. Baptista, J. Am. Ceram. Soc. 1999, $82,3459$.

[14] N. Froumin, M. Eisenstein, M. Polak, Scr. Mater. 1999, 41, 1205.

[15] A. A. Amadeh, J. C. Labbe, P. E. Quintard, J. Eur. Ceram. Soc. 1997, 17, 753.
[16] N. J. Shirtcliffe, S. Aqil, C. Evans, G. McHale, M. I. Newton, C. C. Perry, P. Roach, J. Micromech. Microeng. 2004, 14, 1384.

[17] B. Bohl, R. Steger, R. Zengerle, P. Koltay, J. Micromech. Microeng. 2005, 15, 1125.

[18] S. Vasic, B. Grobety, J. Kuebler, T. Graule, L. Baumgartner, J. Mater. Res. 2007, 5, 114. 